\title{
Preventive Effects of a Major Component of Green Tea, Epigallocathechin-3-Gallate, on Hepatitis-B Virus DNA Replication
}

\author{
Murat Karamese $^{1 *}$, Sabiha Aydogdu $^{2}$,Selina Aksak Karamese ${ }^{3}$, Ulku Altoparlak $^{2}$, \\ Cemal Gundogdu ${ }^{4}$
}

\begin{abstract}
Background: Hepatitis B virus infection is one of the major world health problems. Epigallocatechin-3 gallate is the major component of the polyphenolic fraction of green tea and it has an anti-viral, anti-mutagenic, antitumorigenic, anti-angiogenic, anti-proliferative, and/or pro-apoptotic effects on mammalian cells. In this study, our aim was to investigate the inhibition of $\mathrm{HBV}$ replication by epigallocatechin-3 gallate in the Hep3B2.1-7 hepatocellular carcinoma cell line. Materials and Methods: HBV-replicating Hep3B2.1-7 cells were used to investigate the preventive effects of epigallocatechin-3 gallate on HBV DNA replication. The expression levels of HBsAg and HBeAg were determined using ELISA. Quantitative real-time-PCR was applied for the determination of the expression level of HBV DNA. Results: Cytotoxicity of epigallocathechin-3-gallate was not observed in the hepatic carcinoma cell line when the dose was lower than $100 \mu \mathrm{M}$. The ELISA method demonstrated that epigallocatechin-3 gallate have strong effects on HBsAg and HBeAg levels. Also it was detected by real-time PCR that epigallocatechin-3 gallate could prevent HBV DNA replication. Conclusions: The obtained data pointed out that although the exact mechanism of HBV DNA replication and related diseases remains unclear, epigallocatechin-3 gallate has a potential as an effective anti-HBV agent with low toxicity.
\end{abstract}

Keywords: Hepatitis B - Hepatocellular carcinoma - EGCG - green tea - in-vitro

Asian Pac J Cancer Prev, 16 (10), 4199-4202

\section{Introduction}

Hepatitis B virus (HBV) infection is one of the major world health problems; although the availability of effective vaccines and several antiviral drugs (Baumert, 2007; He, 2011) One third of the world's population has been infected by HBV and 5\% of them are chronically infected according to the World Health Organization (WHO) estimation (Xu, 2008). Some studies show that long-term HBV infection may lead some diseases such as hepatic fibrosis, liver cirrhosis, and hepatocellular carcinoma. Increasing evidence shows that persistent HBV infection in the liver is associated with heavy liver disease, such as cirrhosis and hepatocellular carcinoma (Park, 2006; Pang, 2014).

HBV is a DNA virus consisting of a nucleocapsid which contains the $3.2 \mathrm{~kb}$ circular partially doublestranded DNA genome. The HBV nucleocapsid is surrounded by an envelope. Entry of HBV into healthy hepatocytes has long been recommended as a potential target for antiviral intervention (He, 2011; Huang, 2014). Although several pharmacological treatment strategies have been applied to treat Hepatitis B, a final and exact antiviral therapy against $\mathrm{HBV}$ infection has not been identified. The therapeutic effects of interferon- $\alpha$ and nucleoside analogues, such as entecavir, lamivudine and adefovir, are not fully convincing because such treatments may be accompanied by side effects, high costs and drug resistance (Feld, 2002; Perrillo, 2005; Tillmann, 2009). Several studies reported that some natural products have ability to inhibit HBV replication using various mechanisms. For example, oxymatrine was shown to prevent HBV DNA synthesis (Xu, 2010). A helioxanthin derivative was demonstrated to diminish HBV promoter activities and thus suppress HBV gene expression and DNA synthesis (Ying, 2007; Tseng, 2008). Therefore, there is an urgent and strict necessity to develop highly effective anti-HBV drugs for the long-term treatment of HBV infection with fewer side effects and at a lower cost.

Epigallocatechin-3 gallate (EGCG) is the major component of the polyphenolic fraction of green tea. Along with other tea catechins, and polyphenols in general, it is an antioxidant that is thought to prevent tumorigenesis by protecting cellular components from 
oxidative damage via free radical scavenging. Indeed, a number of studies have demonstrated the free radical scavenging activities of EGCG, as well as its anti-viral, anti-mutagenic, anti-tumorigenic, anti-angiogenic, antiproliferative, and/or pro-apoptotic effects on mammalian cells both in vitro and in vivo (Xu, 2008; Mukhtar, 2000; Hsieh, 2009; Bettuzzi, 2006; Qiao, 2009; Philips, 2009). However, the mechanism by which EGCG inhibits HBV replication is unclear.

In this study, our aim was to investigate the inhibition of HBV replication by EGCG in Hep3B2.1-7 hepatocellular carcinoma cell line. At that point, the results showed that EGCG treatment has a role that reduces the HBV DNA production and $\mathrm{HBV}$ antigens such as $\mathrm{HBsAg}$ and $\mathrm{HBeAg}$ in a dose-dependent manner.

\section{Materials and Methods}

\section{Cell line, cell culture and treatment}

The human hepatocellular carcinoma cell line Hep3B2.1-7 (ATCC: HB-8064) which can stably produce complete virion particles and high levels of $\mathrm{HBV}$ proteins, was purchased from ATCC. It is an inducible HBV replicating cell line and contains a slight over-length HBV genome. In the present study, it was used as a model of HBV-infected hepatocytes. The Hep3B2.1-7 cells were routinely cultured in Dulbecco's modified Eagle's medium (DMEM; Invitrogen) supplemented with $10 \%$ Fetal Bovine Serum (FBS; Gibco, USA), $100 \mathrm{U} / \mathrm{ml}$ penicillin and $100 \mu \mathrm{M}$ streptomycin (Sigma) at $37^{\circ} \mathrm{C}$ in a humidified incubator at $5 \% \mathrm{CO}_{2}$.

Hep3B2.1-7 cells were plated at a density of $1 \times 10^{5}$ cells/ml into 24-well plates and incubated for $24 \mathrm{~h}$. Different concentrations $(0,50,100,200$ and $400 \mu \mathrm{M})$ of EGCG (Sigma, for cell culture) were added to the medium. Cells were grown in the presence of EGCG for $9 \mathrm{~d}$, and the supernatant was collected every other day. After incubation with EGCG for $9 \mathrm{~d}$, the concentrations of $\mathrm{HBsAg}, \mathrm{HBeAg}$, and HBV DNA in the supernatant were determined.

\section{MTT Assay}

The cytotoxicity of EGCG to Hep3B2.1-7 cells was detected by determining the survival rate of the cells using the MTT [3-(4,5-dimethylthiazol-2-yl)-2,5diphenyltetrazolium bromide] method (Liu, 2003). The stock solution of 3-(4, 5-dimethylthiozol-2-yl)-3,5dipheryl tetrazolium bromide (MTT, Sigma) was prepared using sterilized phosphate-buffered saline to $5 \mathrm{mg} / \mathrm{ml}$. Hep3B2.1-7 cells were cultivated at a density of $1 \times 10^{5}$ cells/well in 96-well plates in $100 \mu \mathrm{l}$ and treated with EGCG $(0,50,100,200$ and $400 \mu \mathrm{M})$ for $9 \mathrm{~d}$. The culture medium containing the drugs was changed every other day. On the last day, the culture medium was removed and washed twice with PBS. $10 \mu \mathrm{l}$ of MTT $(5 \mathrm{~g} / \mathrm{ml})$ was added to each well and further incubated in a $\mathrm{CO}_{2}$ incubator at $37^{\circ} \mathrm{C}$ for $4 \mathrm{~h}$. The optical density (OD) at $490 \mathrm{~nm}$ was obtained. Each experiment was performed in triplicate. The inhibition rate of the cells $(\%)$ was calculated as [average value of the control wells (A490-A630)-average value of the study wells (A490-A630)]/average value of the control wells (A490-A630) $\times 100 \%$. The concentration of the drugs with an inhibition percentage of $50 \%$ on proliferating cells (CC50) was calculated according to Berkson logit method (Berkson, 1968).

\section{HBsAg and HBeAg detection by ELISA}

After incubation with EGCG for $9 \mathrm{~d}$, the cell supernatant was collected and subjected to $10000 \times \mathrm{g}$ centrifugation to remove cellular debris. Secreted $\mathrm{HBsAg}$ and $\mathrm{HBeAg}$ were quantified by enzyme-linked Immunosorbent assay (ELISA) kits (DRG, Germany) following the manufacturer's instructions. The data were calculated by the following formula: inhibition of control $(\%)=(1-$ ODT $/$ ODC $) \times 100 \%$, where ODT and ODC represent the cell number-adjusted OD of the test drugs and the control, respectively.

\section{Real-time Quantitative PCR ( $q P C R$ ) detection of $H B V$ DNA}

The quantity of HBV DNA in the culture supernatant and cells was determined with a real-time system (Applied Biosystems, USA) by using. The supernatant of the cells cultured for 6 and $9 \mathrm{~d}$ was collected, and the DNA was extracted from $200 \mu \mathrm{l}$ of medium using the DNA Extraction Kit (QIAGEN) according to the manufacturer's recommendations by an automated system (QIAcube, QIAGEN). The HBV DNA sequence was amplified with a forward primer HBV-DNA-F: 5'-CCTTCTTACTCTACCGTTCC-3', a reverse primer: HBV-DNA-R: 5'-GACCAATTTATGCCTACAGCC-3' and reference gene (Actin): $\beta$-actin-F: 5'-CACCAACTGGGACGACAT-3'. The PCR was initiated by $50^{\circ} \mathrm{C}$ for $2 \mathrm{~min}$ followed by $95^{\circ} \mathrm{C}$ for $10 \mathrm{~min}$, and 40 cycles of $95^{\circ} \mathrm{C}$ for $15 \mathrm{~s}$ and $60^{\circ} \mathrm{C}$ for $10 \mathrm{~s}$. Relative gene expression were calculated by $2^{(-\Delta \Delta \mathrm{Ct})}$ method.

\section{Statistical Analysis}

Statistical analysis was performed by using the SPSS software package (SPSS for windows release 17.0). The one-way ANOVA test was used to evaluate the difference between the test samples.

\section{Results}

The cytotoxicity of EGCG was evaluated by using the MTT assay. Our results showed that EGCG showed significant cytotoxicity to Hep3B2.1-7 cells, above 100 $\mu \mathrm{M}$. As shown in Figure 1, the cytotoxic effects of EGCG was quite slight (10\% inhibition of cell viability) when $100 \mu \mathrm{M}$ of EGCG were used. However, this effect was detected as significantly high (48\% inhibition of cell viability) and (60\% inhibition of cell viability) when 200 and $400 \mu \mathrm{M}$ of EGCG were used, respectively. So that, the maximum non-toxic concentration was $100 \mu \mathrm{M}$, and this was used as the highest concentration of EGCG in the HBV inhibition assay.

The levels of HBeAg and HBsAg in the supernatant of EGCG-treated Hep3B2.1-7 cells were measured by ELISA. The obtained data by ELISA method showed that EGCG inhibit the expression of HBsAg and HBeAg levels in Hep3B2.1-7 cells in a dose-dependent manner. After 
treatment of $9 \mathrm{~d}, 100 \mu \mathrm{M}$ EGCG significantly inhibited the secretion of HBsAg and HBeAg levels by $\% 58,6$ and $\% 48,5$ respectively $(\mathrm{p}<0.05)$. These results indicated that EGCG could down-regulate HBsAg and HBeAg levels (Figure 2).

According to the data that were obtained from qPCR showed us that EGCG could inhibit the production of HBV DNA in a dose-dependent manner. However, after treatment with 50 and $100 \mu \mathrm{M}$ EGCG, a decrease, but not so significant, in the HBV DNA level in the supernatant was observed. The last two concentrations (200 and 400 $\mu \mathrm{M})$ of EGCG could efficiently reduce the extracellular HBV DNA level. Fold changes of HBV DNA expression levels were shown in Figure 3. At that point the data pointed out that at 200 and $400 \mu \mathrm{M}$ concentrations; respectively about $65 \%$ and $80 \%$ of HBV DNA was inhibited effectively after treatment with EGCG $(p<0.05)$.

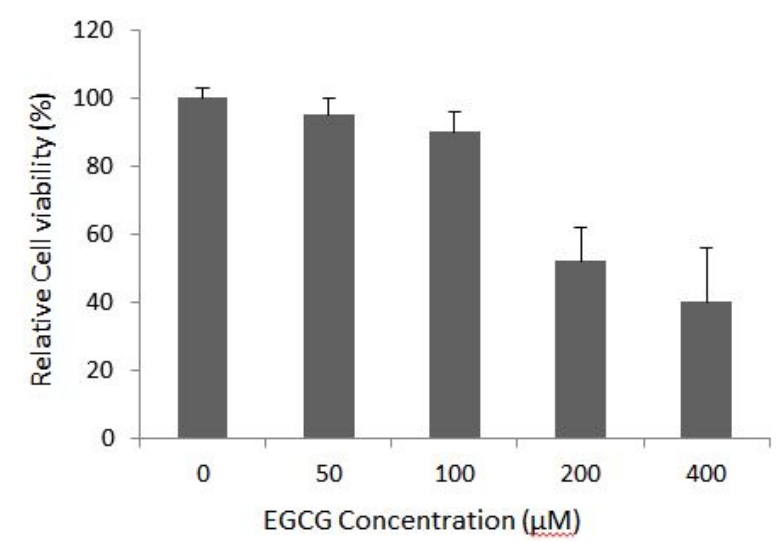

Figure 1.The Cytotoxic Effects of EGCG on Hep3B2.1-7 Cells

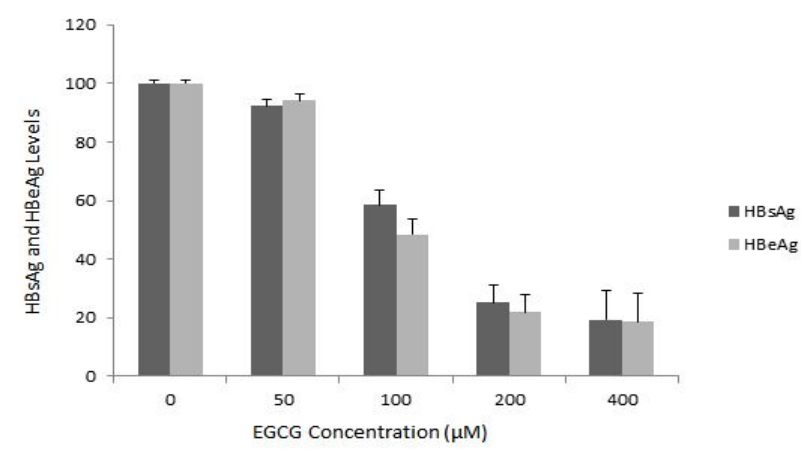

Figure 2. The Effects of EGCG on HBsAg and HBeAg Antigen Expression Levels

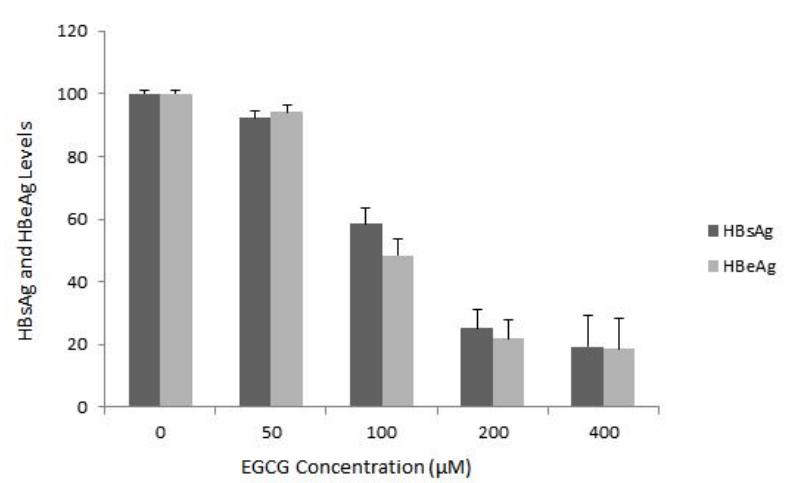

Figure 3. The Preventive Effect of EGCG on HBV DNA Expression Level

\section{Discussion}

Green tea, Camellia sinensis, contains significant amounts of polyphenol catechins such as C, EGC, ECG and EC. EGCG is also one of the catechins and the major compound of green tea (Huang, 2014). Recently, there has been great interest regarding the anti-inflammatory, anti-oxidant, anti-cancer, anti-apoptotic and antiviral properties of polyphenols found in green tea (Liu, 2003; Miyata, 2007; Fassina, 2002; Doong, 1991). Some studies reported that green tea has an activity against some viruses such as HIV, HTLV-1, HCV, Influenza and HBV (Li, 2011; Roh, 2011; Harakeh, 2014; Kim, 2013). EGCG, the major component of green tea, has been demonstrated to show numerous effects, including antiangiogenic, antiproliferative, and apoptotic effects in various tumors, and could inhibit several downstream signaling molecules in multiple signaling pathways (Hastak, 2003). Additionally, EGCG stops the progression of hepatic fibrosis by inhibiting hepatic stellate cell (HSC) activation and matrix metalloproteinase-2 activity (Zhen, 2007).

In this study, we wanted to evaluate the potential antiHBV activity of EGCG in vitro in the Hep3B2.1-7 cell line by analyzing $\mathrm{HBV}$ antigens (HBsAg, $\mathrm{HBeAg}$ ) and $\mathrm{HBV}$ DNA. Our results showed that EGCG could significantly reduce the expression level of HBV DNA. The secretion level of HBeAg and HBsAg compared with control group $(0 \mu \mathrm{M})$ and the results worked in both a dose-dependent manner. Similar data about have been reported with some studies (He, 2011; Xu, 2008).

Green tea polyphenols, especially EGCG, have been demonstrated to have serious efficacy in various models of inflammatory liver injury and are widely used in treatment of human liver diseases such as hepatitis $\mathrm{C}$ and alcoholic cirrhosis (Gloro, 2005). As mentioned above, these polyphenols have an inhibitory effect on some viruses. It can inhibit the expression level of some antigens, receptors or proteins of these viruses such as Epstein-Barr virus, influenza virus, adenovirus and Human Immunodeficiency Virus (Fassina, 2002; Imanishi, 2002; Chang, 2003; Weber, 2003).

Researchers have recently focused on the potential effects of some natural extracts to treat cancers. EGCG is one of them and known to prevent each step of carcinogenesis (Tachibana, 2009; Chen, 2009). Based on this information, we tried to show the preventive effect of EGCG on hepatocellular carcinoma by reducing HBV DNA copies. It is known that detailed replication mechanism of HBV remains unclear. However, it is estimated that various cellular factors are included in HBV genome replication and EGCG may interact with certain cellular proteins and affect the DNA replication mechanism.

As a result, our data showed that EGCG has strong effects on Hepatitis B virus DNA and antigens. Anti-HBV activity of EGCG through decreasing the secretion levels of $\mathrm{HBeAg}$ and $\mathrm{HBsAg}$ and expression level of HBV DNA was shown, parallel with the current literature data. However, to determine whether EGCG treatment could reduce the rates of some diseases -especially liver damage resulting from HBV infection- and to confirm these in- 
vitro studies results, further in-vivo studies are needed. On the other hand, the treatment of HBV all over the world is quite difficult and expensive. This economic situation may lead an extra burden to the countries budget. So that, identification of economic drugs from natural medicines can be a good perspective to solve this problem after antiviral activities of them are exactly proved both invivo and invitro methods. Finally, we can say that although the exact mechanism of HBV DNA replication and related diseases remains unclear, EGCG has a potential as an effective anti-HBV agent with low toxicity.

\section{Acknowledgements}

This study was funded by Ataturk University, Scientific Research Projects Unit by the number of 2013/24.

\section{References}

Baumert TF, Thimme R, von Weizsäcker F (2007). Pathogenesis of hepatitis B virus infection. World J Gastroenterol, 13, 82-90.

Berkson J (1968). Application of minimum logit chi square estimate to a problem of Grizzle with a notation on the problem of 'no interaction'. Biometrics, 24, 75-95.

Bettuzzi S, Brausi M, Rizzi F, et al (2006). Chemoprevention of human prostate cancer by oral administration of green tea catechins in volunteers with high-grade prostate intraepithelial neoplasia: a preliminary report from a oneyear proof-of-principle study. Cancer Res, 66, 1234-40.

Chang LK, Wei TT, Chiu YF, et al (2003). Inhibition of EpsteinBarr virus lytic cycle by (-)-epigallocatechin gallate. Biochem Biophys Res Commun, 301, 1062-8.

Chen L and Zhang HY (2007). Cancer preventive mechanisms of the green tea polyphenol (-)-epigallocatechin-3-gallate. Molecules, 12, 946-57.

Doong SL, Tsai CH, Schinazi RF, et al (1991). Inhibition of the replication of hepatitis B virus in vitro by 2',3'-dideoxy3'-thiacytidine and related analogues. Proc Natl Acad Sci USA, 88, 8495-9.

Fassina G, Buffa A, Benelli R, et al (2002). Polyphenolic antioxidant (-)-epigallocatechin-3-gallate from green tea as a candidate anti-HIV agent. AIDS, 16, 939-41.

Feld J, Locarnini S (2002). Antiviral therapy for hepatitis B virus infections: new targets and technical challenges. $J$ Clin Virol, 25, 267-83.

Gloro R, Hourmand-Ollivier I, Mosquet B, et al (2005). Fulminant hepatitis during selfmedication with hydroalcoholic extract of green tea. Eur J Gastroenterol Hepatol, 17, 1135-7.

Harakeh S, Diab-Assaf M,Azar R, et al (2014). Epigallocatechin3-gallate inhibits tax-dependent activation of nuclear factor kappa B and of matrix metalloproteinase 9 in human T-cell lymphotropic virus-1 positive leukemia cells. Asian Pac J Cancer Prev, 15, 1219-25.

Hastak K, Gupta S, Ahmad N, et al (2003). Role of p53 and $\mathrm{NF}-x \mathrm{~B}$ in epigallocatechin-3-gallate-induced apoptosis of LNCaP cells. Oncogene, 22, 4851-9.

He W, Li LX, Liao QJ, et al (2011). Epigallocatechin gallate inhibits HBV DNA synthesis in a viral replication - inducible cell line. World J Gastroenterol, 17, 1507-14.

Hsieh TC and Wu JM (2009). Targeting CWR22Rv1 prostate cancer cell proliferation and gene expression by combinations of the phytochemicals EGCG, genistein and quercetin. Anticancer Res, 29, 4025-32.

Huang HC, Tao MH, Hung TM, et al (2014). (-)-Epigallocatechin- 3-gallate inhibits entry of hepatitis B virus into hepatocytes. Antiviral Res, 111, 100-111.

Imanish N, Tuji Y, Katada Y, et al (2002). Additional inhibitory effect of tea extract on the growth of influenza A and B viruses in MDCK cells. Microbiol Immunol, 46, 491-4.

Kim M, Kim SY, Lee HW, et al (2013). Inhibition of influenza virus internalization by (-)-epigallocatechin-3-gallate. Antiviral Res, 100, 460-72.

Li S, Hattori T, Kodama EN (2011). Epigallocatechin gallate inhibits the HIV reverse transcription step. Antivir Chem Chemother, 21, 239-43.

Liu ZS, Tang SL, Ai ZL (2003). Effects of hydroxyapatite nanoparticles on proliferation and apoptosis of human hepatoma BEL-7402 cells. World J Gastroenterol, 9, 196871.

Miyata T (2007). Pharmacological basis of traditional medicines and health supplements as curatives. J Pharmacol Sci, 103, 127-31.

Mukhtar H and Ahmad N (2000). Tea polyphenols: prevention of cancer and optimizing health. Am J Clin Nutr, 71, 1698-702.

Pang JY, Zhao KJ, Wang JB, et al (2014). Green tea polyphenol, epigallocatechin-3-gallate, possesses the antiviral activity necessary to fight against the hepatitis B virus replication in vitro. J Zhejiang Univ Sci B, 15, 533-39.

Park NH, Song IH, Chung YH (2006). Chronic hepatitis B in hepatocarcinogenesis. J Postgrad Med J, 82, 507-15.

Perrillo RP (2005). Current treatment of chronic hepatitis B: benefits and limitations. Semin Liver Dis, 25, 20-28.

Philips BJ, Coyle CH, Morrisroe SN, et al (2009). Induction of apoptosis in human bladder cancer cells by green tea catechins. Biomed Res, 30, 207-15.

Qiao Y, Cao J, Xie L, et al (2009). Cell growth inhibition and gene expression regulation by (-)-epigallocatechin-3-gallate in human cervical cancer cells. Arch Pharm Res, 32, 130915.

Roh C and Jo SK (2011). (-)-Epigallocatechin gallate inhibits hepatitis C virus (HCV) viral protein NS5B. Talanta, 85, 2639-42.

Tachibana H (2009). Molecular basis for cancer chemoprevention by green tea polyphenol EGCG. Forum Nutr, 61, 156-69.

Tillmann HL (2007). Antiviral therapy and resistance with hepatitis B virus infection. World J Gastroenterol, 13, 125-40.

Tseng YP, Kuo YH, Hu CP, et al (2008). The role of helioxanthin in inhibiting human hepatitis B viral replication and gene expression by interfering with the host transcriptional machinery of viral promoters. Antiviral Res, 77, 206-214.

Weber JM., Ruzindana-Umunyana A, Imbeault L, et al (2003). Inhibition of adenovirus infection and adenain by green tea catechins. Antiviral Res, 58, 167-73.

Xu J, Wang J, Deng F, et al (2008). Green tea extract and its major component epigallocatechin gallate inhibits hepatitis $\mathrm{B}$ virus in vitro. Antiviral Res, 78, 242-9.

Xu WS, Zhao KK, Miao XH, et al (2010). Effect of oxymatrine on the replication cycle of hepatitis B virus in vitro. World J Gastroenterol, 16, 2028-37.

Ying C, Li Y, Leung CH, et al (2007). Unique anti-viral mechanism discovered in anti-hepatitis B virus research with a natural product analogue. Proc Natl Acad Sci USA, 104, 8526-31.

Zhen MC, Wang Q, Huang XH, et al (2007). Green tea polyphenol epigallocatechin-3-gallate inhibits oxidative damage and preventive effects on carbon tetrachlorideinduced hepatic fibrosis. J Nutr Biochem, 18, 795-805. 